\title{
La suspensión condicional del proceso penal: reflejo de la difícil armonización entre eficiencia y efectividad en los sistemas penales*
}

\section{Rocío González Velázquez**}

\begin{abstract}
RESUMEN
En las últimas décadas, diversos paises latinoamericanos han emprendido reformas procesales-penales de gran calado, entre las cuales se encuentra la introducción de mecanismos para atender asuntos penales al margen del proceso penal y el juicio. Tal es el caso de la suspensión condicional del proceso penal. Este artículo explica, a través del caso de la suspensión condicional del proceso regulada en México, por qué la búsqueda de eficiencia operativa del sistema penal puede comprometer, en últimas, su efectividad para brindar respuestas justas.
\end{abstract}

\section{PALABRAS CLAVE}

Eficiencia, efectividad, sistema penal, suspensión condicional del proceso.

\begin{abstract}
In recent decades, various Latin American Countries have undertaken major criminal-procedural reforms, among which is the introduction of mechanisms to deal with criminal matters outside the criminal process and trial. Such is the case of the Conditional Suspension of Criminal Proceedings. This article explains, through the case of the Conditional Suspension of the process regulated in Mexico, why the search for operational efficiency of the criminal system can compromise, ultimately, its effectiveness to provide fair answers
\end{abstract}

\section{KEYWORDS}

Efficiency, effectiveness, penal system, conditional suspension of the process.

*Artículo recibido el 16 de diciembre de 2017 y aceptado para su publicación el 5 de abril de 2018

*Consultora independiente. (rociogove@gmail.com; rociogove@yahoo.com) orcid.org/0000-0002-6166-8309 


\section{SUMARIO}

1. Introducción

2. La suspensión condicional del proceso penal. Delimitación conceptual y fines que persigue

3. Los fines de la scp en México

4. Tipo de eficiencia privilegiada en la gestión de la scp en la Ciudad de México

5. Razones por las cuales la SCP compromete la consecución de resultados efectivos por parte del sistema penal

6. Conclusiones

\section{Introducción}

En diversas jurisdicciones existen mecanismos destinados a inhibir o suspender el proceso penal, a cambio de que la persona imputada cumpla satisfactoriamente algunas obligaciones. La introducción de tales figuras ocurre al margen de las tradiciones jurídicas y los modelos procesales penales que orientan la gestión de delitos. Las instituciones que paralizan una persecución penal, a cambio de que la persona imputada satisfaga determinadas obligaciones, se sustentan teóricamente en la discrecionalidad de las autoridades penales, para resolver un asunto penal de manera diferente al proceso tradicional.

Estas instituciones tienen como base el denominado principio de autonomía de voluntad de las partes en conflicto. ${ }^{1}$ Además, han sido referidas dentro de la literatura especializada como evidencia de: $a$ ) la desformalización y simplificación de la gestión de determinados asuntos penales (normalmente delitos menores) en detrimento del juicio; b) la incorporación de elementos contractuales dentro de la justicia penal, y c) la integración de nuevas técnicas de control penal. ${ }^{2}$

Aunque desde el siglo XvI diversos países europeos han reconocido algunas modalidades de inhibición condicionada del proceso penal, ${ }^{3}$ fue hasta mediados

\footnotetext{
${ }^{1}$ FlÁvio Gomes, LuIz, "El nuevo paradigma de la justicia criminal consensuada: planteamientos sobre la Ley Brasileña 9.099/95", Boletín de la Facultad de Derecho, núm. 12, p. 370.

2 Se indica que este tipo de instituciones favorecen nuevas formas de control penal.

${ }^{3}$ En los Paises Bajos se tienen registros de la compositie desde el siglo xvI (Spierenburg, 1984, p. 122) y desde 1838 de la transactie; dichas instituciones coinciden en lograr la paralización de las actuaciones penales a cambio de que la persona sospechosa realice el pago de una suma de dinero. Spierenburg, Pieter, The spectacle of suffering: Executions and the evolution of repression: From a preindustrial metropolis to the European experience, Cambridge, Cambridge University Press, 1984; TAK, PETER, "The Dutch Prosecutor. A Prosecuting and Sentencing Officer", En Erik Luna \&t Marianne Wade (eds.), The Prosecutor in Transnational Perspective, Oxford, Oxford University Press. Disponible en: http://doi.org/10.1093/acprof:osobl/9780199844807.003.0011
} 
del siglo xx que se han introducido estas figuras en varios ordenamientos jurídicos, pertenecientes a diversas tradiciones jurídicas. Tal es el caso de la suspensión condicional del proceso (scP, en adelante), institución reconocida en un buen número de países latinoamericanos y en la cual se centra este artículo.

La SCP se regula actualmente en 17 legislaciones procesales de países iberoamericanos de manera más o menos homogénea. ${ }^{4}$ Reconoce su antecedente más cercano en la figura de la suspensión del proceso a prueba, recogida en el Código Procesal Penal Modelo para Iberoamérica. ${ }^{5}$ Sin embargo, algunos sectores doctrinales afirman que el diseño de la scP, incluso el previsto dentro del Código Modelo, proviene de la figura establecida en el parágrafo §153a de la Ordenanza Procesal Penal alemana ${ }^{6}$ o de la pretrial diversion estadounidense. ${ }^{7}$

\section{La suspensión condicional del proceso penal. Delimitación conceptual y fines que persigue}

La ScP constituye una institución (especie) que forma parte de una tipología más amplia de mecanismos condicionales de inhibición o paralización del proceso penal (género). ${ }^{8}$ Ante la presunta comisión de un ilícito, y previa solicitud por parte de las autoridades del sistema penal o de la propia persona imputada, los mecanismos que inhiben condicionalmente el proceso penal permiten distribuir respuestas potencialmente punitivas, al margen del proceso tradicional.

La interrupción del proceso penal se subordina a que la persona imputada acepte, tácita o expresamente, su renuncia al juicio y cumpla determinadas obligaciones. La ejecución satisfactoria de tales obligaciones o cargas por parte de la persona imputada extinguirá la acción penal, sin que la responsabilidad penal de ésta se aclare bajo los estándares probatorios y del debido proceso que orientan

\footnotetext{
${ }^{4}$ En menos de dos décadas, la institución de la suspensión condicional del proceso se ha introducido en los códigos procesales penales de 17 paises Argentina, Bolivia, Brasil, Chile, Colombia, Costa Rica, Ecuador, El Salvador, Guatemala, Honduras, México, Nicaragua, Panamá, Paraguay, Perú, República Dominicana, Venezuela, de manera relativamente homogénea y como parte del paquete de reforma procesal penal. Para una descripción de dicho proceso de refirma, consultar Langer (2007).

${ }^{5}$ Houed VEGA, M. A., De la suspensión del proceso a prueba o de la suspensión condicional de la persecución penal, Nicaragua, Instituto de Estudio e Investigación Jurídica, 2007.

${ }^{6}$ Garcia Aguilar, R., La suspensión del proceso a prueba en materia penal, San José, Investigaciones Jurídicas, 1998, p. 101; Marino, E., "Suspensión del Procedimiento a Prueba", en J. B. J. Maier (ed.), El Nuevo Código Penal Procesal de la Nación, Buenos Aires, Editores del Puerto, 1993, p. 32; Riego, C. y Duce, M., Introducción al Nuevo Proceso Penal. Santiago: Universidad Diego Portales, 2002, p. 302.

${ }^{7}$ Vitale, G. L., Suspensión del proceso penal a prueba, Buenos Aires, Editores del Puerto, 1996, p. 34.

${ }^{8}$ Otras manifestaciones de los mecanismos condicionales tienen representación en los acuerdos reparatorios y algunas modalidades de los criterios de oportunidad, siempre que, para la procedencia de estos últimos, se requiera a la persona imputada el cumplimiento de una obligación de dar, hacer o no hacer.
} 
los juicios. Por el contrario, si la persona imputada incurre en algún incumplimiento de las obligaciones aceptadas, se iniciará el proceso penal o se retomará en el punto en que fue abandonado. Tales mecanismos se sustentan en una presunción de culpa y, según la jurisdicción en que se aplique, pueden dar lugar a registros de carácter administrativo o penal distintos a una condena penal.

La tipología de los mecanismos condicionales reúne nueve propiedades esenciales que permite su distinción respecto de otras instituciones jurídicas con las cuales existe afinidad o cierta confusión. Tal es el caso de los procedimientos simplificados o abreviados; los archivos no condicionados y la suspensión condicional de la ejecución de la pena, principalmente. Entre las propiedades esenciales de esta tipología de mecanismos condicionales destacan:

- Su informalidad, al prescindir de diversos requisitos que deben cumplirse durante el proceso penal;

- Su carácter procesal-penal, pues además de proveer un método de distribución de respuestas penales, los mecanismos condicionales representan una fuente de reacciones potencialmente punitivas que habrán de administrarse entre quienes resulten elegibles;

- La discrecionalidad con la que tales mecanismos son administrados, ya que las autoridades tienen la opción de elegir entre interrumpir un proceso penal para buscar una solución al margen de éste o continuar con el mismo;

- La propiedad de subordinación, pues la paralización definitiva de la persecución penal se condiciona al cumplimiento de una serie de obligaciones de dar, hacer o no hacer por parte de la persona imputada;

- Su propiedad excluyente de diversos principios que se cumplen durante el proceso penal (debido proceso) y el juicio (principio de culpabilidad). Para un sector de la doctrina, ciertos principios y derechos que conforman el debido proceso se ven limitados con la aplicación de los mecanismos de inhibición o paralización condicionada del proceso penal; 9 sin embargo, hay quienes hablan de un nuevo debido proceso, en el cual tiene cabida la voluntad de la persona imputada para elegir, dentro de los derechos y garantías que le asisten, cuáles ejerce y cuáles no; ${ }^{10}$

\footnotetext{
${ }^{9}$ Horvitz Lennon, M. I., \&t López Masle, J., Derecho procesal penal chileno. Jurídica, Santiago, Editorial Jurídica de Chile, 2002, p. 183.

${ }^{10}$ Flávio Gomes, LUIZ, "El nuevo paradigma de la justicia criminal consensuada: planteamientos sobre la Ley Brasileña
} 
- Su atributo de derivación conforme el cual determinados asuntos se desvían del proceso penal y, por tanto, del juicio; tal carácter desjudicializante representa un abandono del juicio como medio para la determinación de la responsabilidad penal y la definición del castigo. ${ }^{11}$

- Su capacidad de instituirse como alternativa frente a otras reacciones penales que derivan del proceso penal, como las penas alternativas no privativas de libertad, e incluso, la prisión;

- Su propiedad de selectividad, mediante la cual el sistema penal realiza un tratamiento diferenciado de los asuntos que ingresan en él, con arreglo a las directrices de política criminal que orienten el tratamiento de los delitos en general, y la aplicación de los mecanismos condicionales en particular (tipo de bien jurídico afectado, ausencia de interés en la investigación, delitos menores), y

- Su carácter simplificador de la gestión del sistema penal, al reducir las actuaciones para la asignación de respuestas penales, en contraste con los requisitos previstos por el proceso penal y el juicio.

La tipología de mecanismos que inhiben o suspenden condicionalmente el proceso penal también puede presentar hasta seis propiedades no esenciales o contingentes, las cuales estarán determinadas por la regulación y aplicación de este tipo de instituciones dentro de una jurisdicción específica. Entre dichas propiedades contingentes se encuentra su carácter consensual, pues se estima que la persona imputada es quien, en el marco de una negociación penal, acepta de manera libre e informada la procedencia de este tipo de mecanismos y las obligaciones que cumplirá como parte de la suspensión del proceso en su contra. ${ }^{12}$ Sin embargo, para que pueda hablarse de consentimiento libre e informado, se debe analizar de manera específica cómo se regula y practica dicha institución, el grado de intervención de la persona imputada para decidir el

9.099/95", Boletín de la Facultad de Derecho, núm. 12.

1 Bovino, A., La suspensión del procedimiento penal a prueba en el Código Penal argentino, Argentina, Editores del Puerto, 2001.

${ }^{12}$ La corriente que justifica la existencia de la scp con base en el principio de la autonomía de la voluntad concibe las cargas que la persona imputada cumple como obligaciones de carácter civil o liberalidades de naturaleza contractual. Galain Palermo, P., "La reparación del daño en un sistema penal funcional a las necesidades de la política criminal", en M. De Hoyos Sancho (ed.), Garantías y derechos de las víctimas especialmente vulnerables en el marco jurídico de la Unión Europea, España, Tirant lo Blanch, 2013.

Se estima que la persona imputada, libre, informada y voluntariamente, acepta tales obligaciones, pues entiende que es el precio a pagar para librarse de un estado de sospecha. Bovino, A., La suspensión del procedimiento penal a prueba en el Código Penal argentino, Argentina, Editores del Puerto, 2001. 
rumbo que seguirá su caso, así como las posibilidades reales de ésta para incidir en la solución final. Por tales razones, esta característica no se debe considerar inherente a la institución ni automática, sino que hace falta analizar cada caso en que se aprueba un mecanismo condicional.

Algunas jurisdicciones, como es el caso de México y Brasil, reconocen tales instituciones como un derecho subjetivo de la persona sospechosa, condicionado al cumplimiento de ciertos requisitos de procedencia (tipo de delito, punibilidad máxima de la conducta imputada, entre otros.

Por otro lado y conforme las Reglas de Kioto, dichas instituciones se pueden considerar disposiciones previas al juicio de carácter comunitario, pues permiten mantener a un presunto delincuente en la comunidad y mitigan el recurso a la prisión. ${ }^{13}$

Esta tipología de instituciones puede presentar la propiedad de supervisión, entendida como la existencia de métodos de asistencia y control a través de los cuales los agentes del sistema penal $u$ otras personas autorizadas por éste dan seguimiento al cumplimiento de las cargas que se imponen como parte de la paralización del proceso penal. En el caso de la scP, tal supervisión se materializa en México a través de la autoridad supervisora, prevista en el Código Nacional de Procedimientos Penales (en adelante, CNPP). ${ }^{14}$

Dichos mecanismos pueden, en determinadas jurisdicciones, conllevar una declaración de responsabilidad penal o una aceptación de los hechos imputados. La exigencia de tales declaraciones se justifica con el propósito de dar por concluida la controversia sobre la responsabilidad penal o asegurar la persecución penal en el caso de que la persona imputada incumpla con las condiciones asumidas.

Finalmente, si la decisión de desviar un asunto fuera del proceso penal recae única o mayoritariamente en la fiscalía o policía, estaremos frente a una institución de carácter administrativo, en contraposición de aquellas decisiones que toma una autoridad judicial.

La introducción de los mecanismos condicionales de inhibición o suspensión condicional del proceso en una determinada jurisdicción puede responder a diversos propósitos de política criminal. ${ }^{15}$ Tales objetivos pueden clasificarse

\footnotetext{
${ }^{13}$ Reglas 2.5 y 5 de las Reglas minimas de las Naciones Unidas sobre las medidas no privativas de la libertad, adoptadas por la Asamblea General en su resolución 45/110, de 14 de diciembre de 1990.

${ }^{14}$ Artículos 176 a 182.

15 UNODC, "The Status and Role of Prosecutors. A United Nations Office on Drug and Crime and International Association of Prosecutors Guide", United Nations Office on Drug and Crime. Diponible en: https://www.unodc.org/ documents/justice.../14-07304_ebook.pdf
} 
en cuatro grandes paradigmas o modelos. Éstos constituyen sistematizaciones analíticas de los distintos argumentos que promueven la regulación y práctica de las instituciones. Por tanto, sirven en el estudio y delimitación de las diversas manifestaciones de parálisis condicionada del proceso penal.

Los cuatro modelos son $a$ ) el despenalizador o descriminalizador; $b$ ) el de la justicia penal negociada, tanto en su vertiente consensual como en la gerencial; c) el de la justicia restauradora, y d) el de la prevención especial, en su versión negativa o incapacitadora y su versión positiva o rehabilitadora.

El modelo despenalizador o descriminalizador pretende evitar la estigmatización de la persona imputada. Para tal efecto, obstaculiza el dictado de una sentencia condenatoria y evita la conformación de antecedentes penales. ${ }^{16}$

Por su parte, el paradigma de la justicia penal negociada busca una solución al conflicto penal. Esto se realiza a través de la concesión de beneficios entre ciertos actores involucrados que se sitúan en condiciones de relativa igualdad (vertiente consensual), ${ }^{17}$ o bien mediante la solución rápida del conflicto, una vez que el sistema penal lo haya detectado (vertiente gerencial). ${ }^{18}$

Entre otros aspectos, el paradigma restaurador persigue atender las necesidades de la víctima y recomponer las relaciones sociales afectadas por el delito. ${ }^{19}$

Por último, el modelo de la prevención especial, en sus modalidades positiva y negativa, procura evitar la comisión de futuros delitos. Para ello, realiza intervenciones de carácter terapéutico que modifiquen el comportamiento de la persona imputada (rehabilitación). ${ }^{20}$ En su caso, puede forzarla al cumplimiento de determinadas obligaciones que obstaculicen su participación en la comisión de futuros delitos (incapacitación y control), respectivamente. ${ }^{21}$

\footnotetext{
${ }^{16}$ Chaple, M., Pretrial Diversion \& Record Sealing: A Promising Approach to Reduce Recidivism among Substance Abusing Offenders, Estados Unidos, University of New Jersey, 2011. Disponible en: https://search.proquest.com/ openview/660407f91200b7ebe70f217bf623f7e3/1?pq-origsite =gscholaretcbl=18750\&diss=y

${ }^{17}$ Tulkens, F., "Negotiated Justice", en M. Delmas-Marty \& J. R. Spencer (eds.), European criminal procedures, Cambridge, Cambridge University Press, 2005.

${ }^{18}$ TAK, Peter, "The Dutch Prosecutor. A Prosecuting and Sentencing Officer", En Erik Luna \& Marianne Wade (eds.), The Prosecutor in Transnational Perspective, Oxford, Oxford University Press. Disponible en: http://doi.org/10.1093/ acprof:osobl/9780199844807.003.0011

${ }^{19}$ Daly, K., "The Punishment Debate in Restorative Justice", en J. Simon \& R. Sparks (eds.), The sage Handbook of Punishment and Society Handbook of Punishment and Society, London, SAGE Publications, 2013.

${ }^{20}$ Andrews, D., \& Bonta, J., The psychology of criminal conduct, New Providence, LexisNexis, 2010. Disponible en: http://doi.org/10.1017/CB09781107415324.004

${ }_{21}^{21}$ Bovino, A., La suspensión del procedimiento penal a prueba en el Código Penal argentino, Argentina, Editores del Puerto, 2001; CHAPLE, M., Pretrial Diversion \& Record Sealing: A Promising Approach to Reduce Recidivism among Substance Abusing Offenders, Estados Unidos, University of New Jersey, 2011. Disponible en: https://search.proquest.com/openview/660407f91200b7ebe70f217bf623f7e3/1?pq-origsite=gscholar\&cbl=18750\&diss=y
} 
Es necesario advertir que dentro de un mismo ordenamiento jurídico pueden convivir de manera simultánea dos o más paradigmas. ${ }^{22}$ Los fines que pretenda alcanzar un mecanismo condicional en particular estarán determinados, en últimas, por las obligaciones o condiciones que una persona imputada deba cumplir a cambio de que se inhiban o suspendan temporalmente todas las actuaciones del proceso penal.

Las cargas adjudicadas a la persona imputada, a pesar de poseer una naturaleza jurídica relativamente autónoma a la del mecanismo que inhibe o suspende el proceso penal, ${ }^{23}$ dependen de éste, ya que existe una relación teórica prescriptiva de interdependencia entre fines esperados con la parálisis del proceso penal y las cargas que debe satisfacer la persona imputada.

En otras palabras, las cargas de hacer, de no hacer o de dar, que asume y cumple la persona imputada determinan, en gran medida, los objetivos que se alcanzarán con la inhibición del proceso penal. Por tal razón, las autoridades responsables de seleccionar y aplicar las condiciones a un caso concreto deben basar sus decisiones en la correspondencia de los cuatro modelos justificadores de los mecanismos condicionales. Asimismo, deben considerar las condiciones que cada uno de los paradigmas admite, de tal manera que exista congruencia entre fines esperados (paradigmas) y medios disponibles (condiciones) (véase la tabla 1).

\section{Los fines de la scr en México}

En México, figuras como la SCP y los acuerdos reparatorios -considerados mecanismos alternativos de solución de controversias en el artículo 17 de la Constitución Política de los Estados Unidos Mexicanos- se introdujeron con motivo de la reforma constitucional en materia de seguridad y justicia penal de 2008. ${ }^{24}$ De acuerdo con los dictámenes y exposiciones de motivos que derivan de las reformas antes aludidas, los fines normativos asignados a los mecanismos alternativos de solución de controversias son la reparación del daño (mo-

190 delo restaurador), la protección a la víctima (modelos restaurador y preventivo), la economía procesal (modelo de justicia negociada gerencialista), y que la

\footnotetext{
${ }^{22}$ Tulkens, F., "Negotiated Justice", en M. Delmas-Marty \& J. R. Spencer (eds.), European criminal procedures, Cambridge, Cambridge University Press, 2005.

${ }^{23}$ Esta es una discusión abierta, sin embargo, algunas voces se pronuncian por considerar las cargas que acompañan a los mecanismos que inhiben condicionalmente un proceso penal como instituciones autónomas, especialmente la doctrina europea.

${ }^{24}$ Decreto por el cual se reforman y adicionan diversas disposiciones de la Constitución Política de los Estados Unidos Mexicanos, publicado en el Diario Oficial de la Federación el 18 de junio de 2008.
} 
persona imputada se responsabilice de las consecuencias de su actuar (modelo preventivo). ${ }^{25}$

Tabla 1. Relación entre los paradigmas que justifican los mecanismos condicionales de inhibición o suspensión del proceso penal y tipo de condiciones o reglas de conducta que admiten

\begin{tabular}{|c|c|c|c|c|}
\hline $\begin{array}{l}\text { Paradigma } \\
\text { o modelo }\end{array}$ & $\begin{array}{l}\text { Despenalizador o } \\
\text { descriminalizador } \\
\text { de facto }\end{array}$ & Justicia negociada & Justicia restauradora & Prevención especial \\
\hline 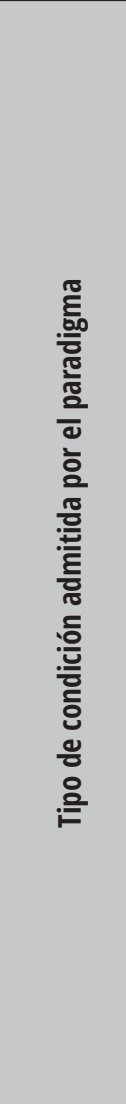 & $\begin{array}{l}\text { - Pago de multa } \\
\text { - Mantener } \\
\text { residencia en lugar } \\
\text { específico; no } \\
\text { delinquir }\end{array}$ & $\begin{array}{l}\text { Consensual } \\
\text { - Cualquier tipo } \\
\text { mientras sea } \\
\text { convenido por las } \\
\text { partes } \\
\text { Gerencialista } \\
\text { - Cualquier tipo de } \\
\text { condiciones, mientras } \\
\text { se priorice la gestión } \\
\text { operativa del sistema } \\
\text { penal }\end{array}$ & $\begin{array}{l}\text { - Reparación del } \\
\text { daño } \\
\text { - Mediación } \\
\text { víctima-delincuente } \\
\text { - Conferencias } \\
\text { o círculos } \\
\text { restauradores } \\
\text { - Trabajo en } \\
\text { beneficio de la } \\
\text { comunidad } \\
\text { - Donación de una } \\
\text { suma de dinero a } \\
\text { una organización civil } \\
\text { o de beneficencia }\end{array}$ & $\begin{array}{l}\text { Positiva-rehabilitadora } \\
\text { - Programas de } \\
\text { deshabituación de } \\
\text { drogas o alcohol } \\
\text { - Programas } \\
\text { educativos } \\
\text { - Capacitación para el } \\
\text { trabajo } \\
\text { - Programas para el } \\
\text { manejo y gestión de } \\
\text { problemas } \\
\text { - Supervisión } \\
\text { rehabilitadora } \\
\text { Negativa- } \\
\text { incapacitadora } \\
\text { - Arresto domiciliario } \\
\text { - Monitoreo } \\
\text { electrónico } \\
\text { - Prohibición } \\
\text { de acercarse a } \\
\text { determinado lugar, de } \\
\text { frecuentar personas } \\
\text { específicas, de portar } \\
\text { armas } \\
\text { - Inhabilitación para } \\
\text { realizar determinada } \\
\text { actividad o ejercer } \\
\text { alguna profesión } \\
\text { - Supervisión con el } \\
\text { fin de control }\end{array}$ \\
\hline
\end{tabular}

Elaboración propia.

${ }^{25}$ Véase el Cuaderno de Apoyo de la Reforma Constitucional en materia de Justicia Penal y Seguridad Pública, elaborado por la Secretaría de Servicios Parlamentarios de la Cámara de Diputados Martinez Monroy, R., Reforma constitucional en materia de justicia penal y seguridad pública. Proceso Legislativo, México, Cámara de Diputados, 2008. 
Por su parte, la Suprema Corte de Justicia de la Nación ha interpretado que el fin preponderante de los mecanismos alternativos de solución de controversias es la restauración. ${ }^{26}$ Sin embargo, al conferir a los mecanismos alternativos una naturaleza de "híbridos con prioridades invertidas", en comparación con el proceso penal, dicho tribunal ha reconocido explícitamente que la retribución -es decir, el castigo- puede ser un objetivo secundario en tales instituciones. En dicha interpretación, la Suprema Corte de Justicia de la Nació también ha dejado claro que los mecanismos alternativos sirven a la despresurización de las altas cargas de trabajo de los órganos judiciales.

Por lo anterior, es posible afirmar que, en términos normativos y jurisprudenciales, los objetivos de la scr en el caso mexicano obedecen, principalmente, al modelo restaurador, así como al paradigma de la justicia negociada, en su vertiente gerencialista.

\section{La eficiencia en instituciones como la scP: significados y alcances}

Los mecanismos condicionales que inhiben o paralizan el proceso penal, como en el caso de la SCP, se han relacionado en diversas jurisdicciones con la búsqueda de eficiencia. El caso mexicano no ha sido la excepción. Se afirma que la introducción de figuras como la scP en el ordenamiento jurídico mexicano ha supuesto la introducción de criterios económicos en el campo de la justicia penal, entre los cuales se encuentra la eficiencia.

El concepto de eficiencia presenta diversas acepciones en el ámbito penal y procesal penal. Para efectos de este artículo, se debe entender por eficiencia aquella relación entre medios y fines que sirve de baremo para evaluar decisiones, programas o políticas públicas, según las consecuencias o resultados que éstas produzcan. Tal valoración se puede realizar de acuerdo con dos escenarios distintos. El primer escenario de eficiencia se corresponde con la maximización de fines. Es decir, con arreglo a determinados medios identificados previamente, se satisface la mayor cantidad de propósitos deseados. El segundo

192 escenario eficiente se refiere a la maximización de medios: la consecución de los fines esperados se logra con la menor utilización de recursos disponibles. ${ }^{27}$

\footnotetext{
${ }^{26}$ Tesis Jurisprudencial 1a./J.33/2017 (10a.), derivada de la Contradicción de tesis 220/2016. En su rubro señala: "Consentimiento del auto de vinculación a proceso. Acontece cuando el imputado acepta concluir el proceso penal a través de un acuerdo reparatorio o suspensión del proceso a prueba, por lo que se actualiza la causa de improcedencia que prevé el artículo 61, fracción XIII, de la Ley de Amparo".

${ }^{27}$ ORTIZ de Urbina, I., "Análisis Económico del Derecho y Política Criminal", Revista de Derecho penal y Criminología, núm. 2, pp. 44-45.
} 
Desde una perspectiva teórica, el concepto de eficiencia que se utiliza en el contexto de instituciones como la scP puede aludir a distintos significados. Esta diversidad de acepciones del concepto depende de qué fines se pretendan conseguir con la aplicación de la SCP -descriminalización, negociación, restauración o prevención-, así como de los medios disponibles para alcanzarlos. Además, los alcances de la eficiencia en instituciones como la ScP varían según se prefiera maximizar los fines esperados o los medios disponibles. A continuación, se describen brevemente algunos de los posibles alcances de la eficiencia, en cada uno de los modelos o paradigmas que justifican la scP.

En el modelo descriminalizador o despenalizador, la aplicación de la scP será eficiente si, ante la participación de la persona imputada en la comisión de un delito, el sistema penal interviene de manera mínima. De tal forma, se obstaculiza la imposición de un castigo, se impiden los efectos criminógenos de una sentencia condenatoria y se mitiga la posibilidad de que dicha persona reincida. ${ }^{28}$

En el paradigma de justicia negociada, en su versión consensual, la eficiencia se puede entender como la maximización de beneficios y utilidades, tanto para la parte que acusa como para la parte acusada. Esto en un contexto donde ambas partes, encontrándose en situación de relativa igualdad jurídica y material, deciden cómo resolverán el conflicto. ${ }^{29}$

En una negociación penal, la paralización condicionada del proceso será eficiente para la parte que acusa si, ante la presunta comisión de un delito, se garantiza una reacción penal sin tener que incurrir en la realización del proceso penal y la celebración de un juicio. Por su parte, la suspensión condicional del proceso será eficiente para la parte acusada si accede a una reacción penal cierta $y$, en teoría, menos severa que la que podría derivar de un juicio.

Por su parte, la eficiencia promovida por la vertiente gerencialista de la justicia penal negociada se circunscribe a la gestión operativa del caso. Este tipo de eficiencia pretende la disposición más rápida de los asuntos que ingresan al sistema penal, ${ }^{30}$ o bien persigue la minimización de los costos directos asociados al funcionamiento del sistema de resolución de conflictos. ${ }^{31}$ Puesto que el propósito será resolver un conflicto penal en el menor tiempo posible o

\footnotetext{
${ }^{28}$ Valverde, M., \& O'Malley, P., "Criminology", en M. Valverde (ed.), The Oxford Handbook of Criminal Law, Oxford, Pat O'Malley, 2014.

${ }^{29}$ DAMASKA, M., "Negotiated Justice in International Criminal Courts", Journal of International Criminal Justice, núm. 2.

${ }^{30}$ Macdonald, S., "Constructing a Framework for Criminal Justice Research: Learning from Packer's Mistakes", New Criminal Law Review, vol. 11, núm. 2. Disponible en: http://doi.org/10.1525/nclr.2008.11.2.257

${ }^{31}$ FIX-Fierro, H., "Tribunales, justicia y eficiencia", Estudio sociojurídico sobre la racionalidad económica en la función judicial México, núm. 76, p. 49.
} 
con el más bajo coste, el foco se pondrá en los recursos disponibles dentro del sistema penal o en los costos que éste debe asumir al atender un asunto.

En la modalidad gerencialista de la justicia negociada, se estima que los delitos menores o aquellos ilícitos cuya persecución carece de interés público pueden ser resueltos de manera satisfactoria, sin necesidad de incurrir en todas las formalidades inherentes al proceso penal. Así, se da una disposición temprana de tales asuntos y se reducen los costos directos que conllevaría su resolución por la vía tradicional. El paradigma gerencialista de la justicia negociada no sólo puede beneficiar al sistema penal, sino que también ofrece ventajas a la persona imputada, quien, de continuar sujeta a las actuaciones penales tradicionales, podría enfrentar una serie de perjuicios y costos propios del proceso penal, ${ }^{32}$ con independencia de su inocencia o culpabilidad. ${ }^{33}$

En el modelo restaurador, suspender condicionalmente un proceso penal será eficiente si se logran restaurar los lazos sociales rotos y se repara el daño ocasionado a la víctima del delito; o bien, si el conflicto se resuelve con una mínima intervención de los profesionales del sistema penal y la menor exposición posible de la persona imputada como responsable de un delito frente a la víctima y a la comunidad. ${ }^{34}$

Por último, en el modelo de prevención, se estima que la aplicación de la scP será eficiente si se evita la reincidencia de la persona imputada, siempre que ésta sea sometida a aquella intervención terapéutica menos invasiva (vertiente rehabilitadora). También es posible alcanzar la eficiencia si la persona imputada es sometida a las menores limitaciones posibles para impedir su involucramiento en conductas delictivas (vertiente incapacitadora).

Una vez que han quedado delimitados algunos de los distintos alcances que el término eficiencia puede desplegar en el caso de la SCP, parece importante indagar qué tipo de eficiencia es la que se privilegia en México, aspecto que se analiza en la siguiente sección.

\footnotetext{
${ }^{32}$ Con base en el análisis de Feeley, el proceso penal conlleva diversos costos que recaen sobre la persona imputada, con independencia de su inocencia o culpabilidad. Entre ellos, se encuentra la privación total de libertad cuando se determina la prisión preventiva; los costos asociados al ejercicio de los derechos y garantías que se reconocen a la persona imputada a través del proceso penal (pago de honorarios a abogados para ejercer el derecho de defensa adecuada), así como los costos relacionados con la necesidad de conciliar el proceso penal y la vida personal (reducción salarial por ausencias laborales para atender audiencias).

${ }^{33}$ FEELEY, M. M., The process is the punishment: handling cases in a lower criminal court, Nueva York, Russell Sage Foundations, 1992.

${ }^{34}$ Bralthwalte, J., "Diversion, reintegrative shaming and republican criminology", en G. Albrecht (ed.), Diversion and Informal Social Control, Berlin, Walter de Gruyter, 1995.
} 


\section{Tipo de eficiencia privilegiada en la gestión de la SCP en la Ciudad de México}

Del análisis de la exposición de motivos de la reforma constitucional al proceso penal de 2008, y del criterio jurisprudencial que sostiene la Suprema Corte de Justicia de la Nación en la contradicción de tesis 220/2016, se deduce que la SCP privilegia, junto con la reparación del daño, la eficiencia relacionada con el modelo de justicia negociada, en su versión gerencialista. Tanto el discurso normativo como la interpretación judicial indican que la scP sirve a la economía y simplificación procesales y a la despresurización de la carga de trabajo al interior de las organizaciones de los sistemas penales. Sin embargo, para corroborar esta apreciación, es necesario explorar algunos resultados de la aplicación de la scr.

A continuación, se presentan algunos de los resultados de una investigación empírica que examina la gestión de la scP en la Ciudad de México, durante el periodo comprendido entre enero de 2015 y abril de $2017 . .^{35}$ Dicha investigación, realizada mediante la metodología de estudio de caso, ${ }^{36}$ analiza información proveniente de diversas fuentes directas e indirectas. Entre éstas, se mencionan $a$ ) la observación de audiencias relacionadas con la concesión y gestión de la $\operatorname{scP}^{37}$ b) la observación de diversos actos relacionados con la supervisión de la scp; ${ }^{38}$ c) la realización de entrevistas a personas imputadas y a diversas autoridades que interactúan en la gestión, en el cumplimiento y en el seguimiento de la scP, ${ }^{39} \mathrm{y} d$ ) información relacionada con la administración

\footnotetext{
${ }^{35}$ Investigación que forma parte de la tesis de doctorado titulada "Los mecanismos condicionales de inhibición y suspensión del proceso penal. Estudio sobre su contenido punitivo y su problema de inocencia", cuyo registro puede consultarse en http://www.tdx.cat/.

${ }^{36}$ Se considera como una metodología, método o estrategia de investigación. La metodología de estudio de caso se recomienda cuando el interés recae en procesos de toma de decisión y en la descripción de eventos, procedimientos o políticas, especialmente si la persona que realiza la investigación tiene poco control sobre los fenómenos analizados o si los límites entre el objeto de estudio y el contexto que le rodea no son claros. El estudio de caso permite la incorporación de una amplia variedad de fuentes de información, tanto cuantitativas como cualitativas.

${ }^{37}$ Se realizó observación semiestructurada de ocho audiencias de gestión de la SCP (concesión, revisión de condiciones, cumplimiento), celebradas en los juzgados de dos centros de reclusión de la Ciudad de México (Reclusorio Norte y Reclusorio Oriente) y se eligieron aleatoriamente.

${ }^{38}$ Se realizó observación semiestructurada de ocho entrevistas de encuadre entre la persona imputada y la autoridad que supervisa el cumplimiento de las condiciones y reglas de conducta. También se observaron, de manera no estructurada, distintas actividades que las autoridades supervisoras realizan para vigilar el cumplimiento de las condiciones y reglas de conducta por parte de las personas imputadas.

${ }^{39}$ Se realizaron tres entrevistas individuales focalizadas a personas imputadas seleccionadas mediante un muestreo propositivo. El principal objetivo de esta entrevista consistió en valorar la experiencia que ha supuesto el cumplimiento de la ScP para dichas personas (véase el anexo 1). Además, se realizaron entrevistas semiestructuradas individuales a tres autoridades supervisoras de la SCP, a dos jueces, a un defensor y a dos especialistas en el tema. Se
} 
y tramitación de la scP en la Ciudad de México. Esta información proviene de datos localizados en páginas de internet o de diversas autoridades, con previa solicitud. ${ }^{40}$ El análisis global de los datos mencionados anteriormente ha servido, entre otros aspectos, para desentrañar qué tipo de eficiencia se privilegia con la tramitación de la SCP en la Ciudad de México.

Primero, al analizar el tipo de asuntos que ha dado lugar a una scP entre enero de 2015 y febrero de 2017 en la Ciudad de México, se advierte que dicha institución permite gestionar supuestas conductas ilícitas consideradas menores y de mediana gravedad. De acuerdo con una base de datos proporcionada por la autoridad supervisora de la scP en la Ciudad de México, los robos simples cometidos sin violencia representan cerca de la mitad de los casos derivados a dicho mecanismo alternativo (49\%). Los delitos contra la salud, tanto por posesión simple, como por la comercialización y suministro de sustancias prohibidas, representan cerca de un 10\% de las scP concedidas en dicho periodo.

De las ScP aprobadas, 6.5\% derivan de conductas posiblemente constitutivas de violencias familiares. Las conductas relacionadas con delitos violentos ${ }^{41}$ o contra las personas, así como otros delitos ${ }^{42}$ representan aproximadamente 4.5\% de las ScP aprobadas durante el periodo referido. En los casos restantes registrados en la base de datos (30\%) no se cuenta con la información necesaria para distinguir el tipo de conducta imputada.

Segundo, la scP en la Ciudad de México se concede, la mayoría de las veces, en la etapa más temprana del proceso penal. Algunos autores asocian la posibilidad de alcanzar resultados eficientes mediante la scP con el momento procesal en que se aprueba ésta, y se recomienda su utilización en la fase procesal más temprana. ${ }^{43}$ Por su parte, el artículo 193 del cNPP prevé que la scP se solicite una vez que la autoridad judicial de control haya dictado el denominado auto de

logró realizar también entrevistas semi-estructuradas grupales a cuatro autoridades supervisoras de la ScP y a tres asesores de víctimas (véase el anexo 1).

${ }^{40}$ Entre dicha información, se encuentra una base de datos proporcionada por la autoridad supervisora, la cual incluye datos generales de 2220 casos de ScP gestionadas ante la Unidad de Supervisión, desde enero de 2015 a febrero de 2017. También se incluyen diversos informes estadisticos, de actividades, de evaluación, y otro tipo de información disponible en las páginas web oficiales de las instituciones involucradas, u obtenida a través del ejercicio de acceso a la información. Aunque los datos recibidos presentaban inconsistencias en algunos puntos, o falta de especificidad en otros, se consideró útil explotarlos para presentar una imagen aproximada de lo que ocurre con la scp en la Ciudad de México.

${ }^{41}$ La categoría delitos contra las personas y otros violentos incluye los siguientes delitos: abuso sexual, maltrato animal, disparo de arma de fuego, homicidios culposos y lesiones.

${ }^{42}$ La categoria otros incluye los siguientes delitos: ataques a las vías de comunicación, cohecho, daños a la propiedad, contra el ambiente, encubrimiento por receptación, falsificación de documentos, quebrantamiento de sellos de la autoridad, fraude, uso de documentos falsos, resistencia de particulares y usurpación de funciones o de profesión. ${ }^{43}$ Vasconcelos Méndez, R., "La suspensión del proceso penal a prueba", Revista del Instituto de la Judicatura, núm. 123. 
vinculación a proceso ${ }^{44} \mathrm{y}$ antes de que se acuerde la apertura del juicio oral. En otras palabras, la scP se puede solicitar durante la etapa de investigación y la intermedia del proceso penal.

De acuerdo con información proporcionada por el Tribunal Superior de Justicia de la Ciudad de México, previa solicitud de información, 71\% de las SCP aprobadas durante el periodo comprendido entre el 16 de enero de 2015 y el 30 de abril de 2017 se gestionaron en la audiencia inicial. Por tanto, la mayoría de las scP se resolvieron durante la actuación que da inicio formal al proceso penal (artículo 211 del cNPP) y cuyo propósito es que la autoridad judicial supervise y controle la labor de la policía y fiscalía. Las ScP restantes (29\%) se tramitaron en audiencia distinta a la inicial, normalmente, durante la etapa de investigación complementaria. ${ }^{45}$

Según una autoridad entrevistada (autoridad de supervisión número 5), aproximadamente 90\% de las scP que se aprueban en audiencia inicial se conceden a personas detenidas por algún supuesto de flagrancia. ${ }^{46}$ De ser cierta esta cifra, las scP aprobadas en audiencia inicial que provienen de una investigación previa representarían únicamente cerca de 10\%.

Al cruzar las cifras del total de scP concedidas y el porcentaje de aquellas resueltas en casos iniciados por flagrancia, se tendría que más de 60\% de las ScP gestionadas durante el periodo analizado fueron aprobadas mientras se encontró detenida la persona imputada y transcurridas entre 48 y 72 horas desde el momento en que ésta fue presentada ante la fiscalía. ${ }^{47}$

\footnotetext{
${ }^{44} \mathrm{El}$ auto de vinculación a proceso es la resolución que dicta el juez de control en una etapa inicial del proceso. A través de ella, se fijan los hechos por los cuales se seguirá el proceso y la investigación. Para dictar esta resolución, se requiere que la fiscalía haya formulado imputación, es decir, que haya comunicado a la persona imputada que existe una investigación en su contra y cuáles son los hechos que la originan. Además, la persona imputada debe haber contestado los cargos si fuese su voluntad y, desde la perspectiva del juez de control, deben existir indicios sobre la comisión del delito y de que la persona imputada participó en el mismo (artículos 307-313; 316-318 del cnpp).

${ }^{45}$ Datos derivados del análisis de información proporcionada por el Tribunal Superior de Justicia de la Ciudad de México y por la Unidad de Supervisión de Medidas Cautelares y Suspensión Condicional del Proceso adscrita a dicho tribunal. ${ }^{46}$ Conforme el cnpp (artículo 146), existe flagrancia cuando la persona imputada es detenida por la autoridad u otra persona en el momento mismo en que supuestamente comete un delito. Asimismo, si la persona es perseguida de manera ininterrumpida tras haber cometido un delito, o bien, sin que la persona imputada sea sorprendida en el momento de la comisión del delito, una tercera persona la señale y se encuentre algún objeto del delito durante la detención.

${ }^{47}$ Este cálculo se realiza bajo la estimación de que las personas detenidas en flagrancia, por regla general, pasan un máximo de 72 horas detenidas antes de que se celebre la audiencia inicial (48 horas ante el ministerio público y 24 horas en un centro de reclusión, después de que la persona imputada ha sido puesta a disposición de la autoridad judicial). El cnPP (artículo 308) indica que inmediatamente después de que la persona imputada sea puesta a disposición de la autoridad judicial de control se citará a la audiencia inicial. Son estimaciones basadas en los plazos que dispone la normatividad. Es posible que en la práctica los tiempos sean mayores o menores.
} 
Ahora bien, entre enero de 2015 y marzo de 2017, cerca de 38\% de los asuntos que recibieron una disposición judicial específica en la jurisdicción local de la Ciudad de México se encauzaron a la ScP. ${ }^{48}$ Por tanto, es posible estimar que, en dicho periodo, más de $20 \%$ de los casos penales resueltos por las autoridades judiciales de esa ciudad, a través de la ScP, recibieron una disposición específica dentro de los primeros días después de que el sistema penal detectara el asunto y la persona sospechosa se encontrara detenida.

La rapidez con la cual se resuelven posibles hechos constitutivos de delitos a través de la scr en la Ciudad de México es paralela a la que tiene lugar en otras jurisdicciones mexicanas. En un estudio realizado en el Estado de México, se encontró que 33.4\% de salidas alternas (scP y acuerdos reparatorios) se concretan en un día, y casi la mitad de ellas (46\%) entre uno y siete días. ${ }^{49}$

Puesto que la mayoría de los hechos derivados a la SCP fueron detectados en flagrancia, se podría argumentar que tales asuntos han sido resueltos de manera eficiente, al disponer los mismos en una etapa temprana, por un lado, y al evitar que el sistema incurra en los costos directos asociados al proceso penal. Sin embargo, esta apreciación parte de dos asunciones no siempre sostenibles. La primera de ellas consiste en dar por hecho que la actuación policial y de la fiscalía se da conforme a derecho. La segunda asume que una persona detenida en flagrancia cometió un delito.

Sin embargo, durante algunas entrevistas realizadas a actores expertos del sistema penal en la Ciudad de México se refirieron casos derivados a la SCP en los cuales posiblemente se presentaron malentendidos en la apreciación de los hechos por parte de la autoridad policial o la fiscalía, o bien asuntos en los que prevalecía alguna circunstancia eximente de responsabilidad penal. Entre tales supuestos, se mencionan casos de personas que hurtaron en estado de necesidad; el de personas imputadas por robo simple -por un malentendido, no realizaron el pago de un producto junto con el resto de las compras- o el de personas que, por prejuicios, fueron acusadas falsamente de una tentativa de robo.

Además, el concepto legal de flagrancia previsto en el cNPP (artículo 146) 198 abre el camino a posibles errores, pues a través de la denominada flagrancia por señalamiento se faculta a cualquier persona para detener a otra que sea señalada por la víctima o un testigo. Esto en caso de que la localización o búsqueda de la persona que se tiene por presunta responsable haya sido ininterrumpida y exista información que haga presumir fundadamente que ésta intervino en

\footnotetext{
${ }^{48}$ Información proporcionada por el propio tribunal.

${ }^{49}$ Fondevilia, G., Langer, M., Bergman, M., Vilalta, C. y Mejia, A., "¿Cómo se juzga en el Estado de México?", México Evalúa. Disponible en: mexicoevalua.org/wp-content/uploads/2016/10/Como_Juzga_Edomex.pdf
} 
dicho delito, o bien se le encuentre en posesión de algún instrumento usado en o derivado del delito. Este supuesto legal abre la puerta a posibles equivocaciones, como la identificación errónea de personas por parte de testigos o la detención de personas inocentes. Además, policías de investigación de la Ciudad de México han reconocido informalmente que deben cubrir una cuota mínima de detenidos en flagrancia para tener derecho a descansos semanales. ${ }^{50}$ Todo ello apuntaría hacia la posibilidad de detenciones ilegales o en las que ha mediado un error.

Los resultados que proyecta la práctica de la scp en la Ciudad de México permiten afirmar que dicha institución sirve para reducir el número de asuntos atendidos mediante el proceso penal y el juicio, así como para minimizar los costos directos que el sistema penal asume para su atención. De tal modo, se confirma una preferencia por la eficiencia operativa frente a otros posibles resultados.

Sin embargo, se advierte que la práctica de la scP también supone costos para las personas imputadas, especialmente cuando se incurre en un error. La probabilidad de incurrir en errores con motivo de la aplicación de la SCP (por ejemplo, su aplicación a personas inocentes) y los costos asociados a tales errores son elementos que deberían formar parte de cualquier valoración integral de eficiencia que se haga de esta institución. Tal evaluación debe considerar, además del criterio de eficiencia, aspectos relacionados con la eficacia de dicha institución para lograr los fines deseados y proporcionar respuestas justas. Este aspecto se revisa en la siguiente sección.

\section{Razones por las cuales la ScP compromete la consecución de resultados efectivos por parte del sistema penal}

Los términos eficiencia y efectividad no son sinónimos. En el ámbito normativo, ambos hacen alusión a valores y cualidades que deseables en un proceso de toma de decisión, un procedimiento o una política pública. La efectividad, además de incluir la eficiencia, comprende también la eficacia, la cual refiere a la consecución real de los objetivos planteados. Que algo sea efectivo significa que tiene la capacidad de alcanzar los propósitos deseados, con una previa maximización de los medios empleados.

En el caso de la ScP, existen diversos obstáculos para que esta institución favorezca la consecución efectiva de los distintos propósitos que se le atribuyen.

\footnotetext{
${ }^{50}$ RoLdÁN, N., "¿Por qué los delitos quedan impunes en la CDmx? Policias narran qué pasa en los mp". Animal Político, 26 de diciembre. Disponible en: http://www.animalpolitico.com/2016/12/investigacion-policia-impunidad-cdmx/
} 
El principal fin normativo declarado de la scP en México es la restauración ${ }^{51} \mathrm{y}$ el cNPP ordena la reparación del daño en todos los casos en que se acuerde una SCP, siempre que ello sea posible (artículos 191, 194 y 196 del cNPP). Sin embargo, de acuerdo con la información proporcionada por el Tribunal Superior de Justicia de la Ciudad de México, sólo en 13\% de las SCP aprobadas durante el periodo estudiado se impuso un plan de reparación del daño.

El bajo número de asuntos en los cuales se ordena la obligación de reparar el daño se puede explicar, en parte, por la dificultad de identificar víctimas específicas de ciertos delitos ${ }^{52}$ y por la recuperación posterior del bien afectado. ${ }^{53}$ Sin embargo, llama la atención que incluso en delitos en los que hay víctimas identificadas (violencias familiares, delitos violentos y contra las personas), la reparación del daño se imponga ocasionalmente.

La determinación de un plan de reparación del daño no alcanzó 50\% de los casos admitidos en ninguna categoría delictiva. Sobre este punto, el cNPP (artículo 196) prescribe que la falta de recursos de la persona imputada no podrá ser utilizada como razón suficiente para rechazar la suspensión condicional del proceso. Esta previsión, sumada a la práctica de asimilar la reparación del daño a una cantidad de dinero, pueden explicar los bajos índices en los que se determina un plan de reparación del daño. La mínima frecuencia con la que se impone la reparación del daño pone en tela de juicio los supuestos beneficios inmediatos que, según la Suprema Corte de Justicia de la Nación, genera la ScP, entre los cuales se refiere la reparación del daño a la víctima.

Por otro lado, la scP sólo podría ser una estrategia de justicia restauradora en los casos en que la víctima participe en la determinación sobre la conveniencia de suspender el proceso. Asimismo, cuando convenga libremente con el imputado los términos del plan de reparación del daño y dicha interacción se dé en un ambiente informal que satisfaga los principios y valores de la justicia restauradora. Sin embargo, en la práctica de la scP, se mantienen formalidades propias del sistema penal.

Con base en las observaciones de audiencias y en las entrevistas a autoridades judiciales, se advirtió de manera importante la voluntad de los actores expertos del sistema penal de alcanzar "resultados" con la mayor rapidez

\footnotetext{
${ }^{51}$ Rios Espinoza, C. (2008). Redesigning Mexico's Criminal Procedure: The States' Turning Point. SW. J. Int'l L., 15, 5482; scjn. Contradicción de Tesis 220/2016, Tomo I Gaceta del Semanario Judicial de la Federación 422 (2017).

${ }^{52}$ Ese argumento se emplea en los delitos contra la salud, debido a que la víctima es la sociedad en su conjunto y el daño no resulta cuantificable en términos económicos.

${ }^{53}$ En los delitos de carácter patrimonial es común que la víctima, persona física o jurídica, recupere el bien afectado antes de que se apruebe la scP.
} 
posible, relegando los fines restauradores a un segundo plano. Además, durante las entrevistas realizadas a las autoridades de supervisión y a quienes tienen a su cargo la asesoría jurídica de víctimas, se percibió la ausencia de criterios sobre quién o quiénes son responsables de dar seguimiento al cumplimiento de la reparación del daño y en qué medida deben apoyar a la víctima para hacer exigible sus derechos.

Por lo descrito anteriormente, estimo que la situación que enfrentan las víctimas durante la tramitación de la SCP pone en seria duda la eficacia y efectividad de la institución, especialmente si se evalúa desde el rasero del fin normativo primario que persigue dicha institución, representado por la restauración.

En relación con los propósitos descriminalizadores o despenalizadores de la SCP y en atención a una perspectiva histórica que contemple el funcionamiento del sistema penal en la Ciudad de México -desde antes de la regulación de la ScP y posterior a la introducción de ésta-, se puede sostener que la institución bajo análisis ha podido significar una reducción en la intensidad de la respuesta penal en ciertas conductas. Antes de la existencia de la scP, resultaba común que personas de bajos recursos y procesadas por robos simples pasaran largos periodos en prisión preventiva y recibieran condenas privativas de libertad. ${ }^{54}$ Actualmente, la persona a quien se le imputa dicha conducta tiene la posibilidad de estar fuera de prisión, aunque con determinadas restricciones a sus libertades. Esta situación apunta a que la scP puede minimizar la intensidad de la respuesta penal, especialmente en aquellas jurisdicciones que abusan de la prisión preventiva.

Sin embargo, figuras como la scP proceden con un bajo estándar de prueba, inhiben la verificación de la existencia de material probatorio por parte de la autoridad judicial y contribuyen a mantener en la opacidad la labor de la policía. Por tales razones, persisten los riesgos e incentivos -por ejemplo, el sistema de cuotas de personas detenidas- para que se produzcan detenciones arbitrarias e ilegales. Esto, en una franja de ilícitos, donde los actores involucrados, y posiblemente la persona imputada, preferirán una resolución cierta y rápida a través de la scP, sin importar si hay medios de prueba idóneos y relevantes que sustenten la imputación.

\footnotetext{
${ }^{54}$ De acuerdo con una encuesta realizada en 2003 en centros de reclusión de la Ciudad de México (entonces Distrito Federal) y el Estado de México, del total de internos, casi 25\% lo eran por robo simple menor a mil pesos, y 50\% por uno menor a seis mil. Bergman, M., Azaola, E., Magaloni, A. L., y Negrete, L., Delincuencia, marginalidad y desempeño institucional: resultados de la encuesta a población en reclusión en el Distrito Federal y el Estado de México, Ciudad de México, CIDE, 2003.
} 
En relación con la versión consensual de la justicia negociada, tanto la normativa como la interpretación jurisprudencial mexicanas sobre la SCP reconocen que la persona imputada es el actor clave en la aprobación de dicho mecanismo alternativo. Sin embargo, con base en la observación de audiencias, en las entrevistas a personas imputadas, así como en el análisis estadístico de los asuntos derivados a la scp durante el periodo de estudio, se advierte que su gestión cotidiana en la Ciudad de México impide que la persona imputada preste su consentimiento libre e informado durante la aceptación de la scP. Además, la gestión de este mecanismo dificulta la participación de la persona imputada en la definición de las condiciones que asumirá.

La audiencia inicial, como escenario en que se propone y acepta la mayoría de las SCP, dificulta a la persona sospechosa entender las implicaciones de sus decisiones, así como las distintas opciones que tendría a su alcance. Lo anterior se explica, en parte, por las circunstancias de modo, tiempo y lugar que rodean la toma de decisiones de la persona imputada.

La mayoría de las veces la persona imputada asiste a la audiencia hallándose detenida y sin haber recibido información adecuada sobre sus derechos y los posibles cauces que podría adoptar su asunto. Por otra parte, la audiencia en que se resuelve la procedencia de la scr es un acto solemne, en el cual se emplea un lenguaje accesible para las autoridades presentes, pero desconocido para la persona imputada. Además, es habitual que sólo las autoridades intervinientes conozcan las reglas y actuaciones que dan contenido a dicho acto, por lo cual la persona imputada adopta casi siempre el papel de mera espectadora.

Por regla general, la persona imputada y su defensa se conocen por primera vez durante los minutos previos al inicio de la audiencia. Si el defensor considera viable la aplicación de la scP al caso concreto, sugerirá a la persona imputada su aceptación, sin que medie una explicación profunda de las implicaciones que conlleva dicho mecanismo y sin una valoración adecuada de qué condiciones serían asequibles para la persona imputada.

Las tres personas imputadas que se entrevistaron adujeron que los principales motivos para aceptar la scP fueron la experiencia de la detención; el trato de las autoridades de la policía y la fiscalía; el riesgo de permanecer un tiempo en prisión preventiva, y la presentación de la scP como la mejor opción posible por parte de la defensoría pública. Esto incluso sin que hayan comprendido totalmente las consecuencias de la SCP y sin haber valorado las implicaciones que las obligaciones impuestas por el juez tendrían sobre su esfera de derechos y libertades. En estos escenarios, resulta equivocado suponer que la autonomía 
de la voluntad de la persona imputada es el mecanismo capaz de explicar la aceptación de la scr.

Por lo que se refiere a la justicia negociada, vertiente gerencialista, el problema del diseño de la scP consiste en estimar factible la convivencia de un sistema fiable de establecimiento de responsabilidades penales con la rapidez. Es posible que en la scP participen personas inocentes, quienes serán consideradas presuntas responsables de los delitos imputados para efectos de su cumplimiento. La falta de reconocimiento de esta institución como un dispositivo propenso al error transfiere los costos de los desaciertos del sistema a las personas imputadas, quienes podrán sufrir limitaciones a diversas libertades y derechos como consecuencia de las obligaciones que deben cumplir, restricciones que pueden persistir por un periodo mínimo de seis meses y hasta un máximo de cinco años.

Por otro lado, bajo el modelo de prevención, cuando una SCP se aprueba en audiencia inicial y deriva en la imposición de condiciones de carácter rehabilitador o incapacitador, no se cuenta con la evaluación previa que permita individualizar las condiciones e identificar las posibles necesidades criminógenas de la persona imputada (artículo 195 del cNPP).

Aunque la autoridad que supervisa la scP en la Ciudad de México sí realiza entrevistas a personas detenidas cuyos casos son eventualmente suspendidos condicionalmente, dicha evaluación sirve para valorar el riesgo procesal de aquéllas y no para identificar sus necesidades criminógenas (artículo 156 del cNPP). Frente a la ausencia de evaluación previa, es factible que la autoridad judicial ordene el cumplimiento de condiciones desproporcionadas, poco idóneas, innecesarias o inadecuadas para atender los problemas que originaron el conflicto.

\section{Conclusiones}

Un balance de la aplicación de la scP en la Ciudad de México permite afirmar que ésta se desarrolla principalmente bajo el modelo gerencialista. La falta de satisfacción de los fines primarios de restauración que orientan la regulación de la ScP en México se debe, en parte, a la incompatibilidad entre éstos y las funciones secundarias asignadas a la scP, tales como la descongestión de los órganos judiciales y la simplificación de las actuaciones procesales.

Difícilmente se tendrán condiciones para generar procesos y resultados restauradores si la gestión de la scP, además de dejarse en manos de los profesionales del sistema penal, persigue con mayor interés la aparente solución de 
un asunto en la etapa más temprana posible, en lugar de escuchar y atender a la víctima.

En la Ciudad de México, además de que la scP pocas veces satisface las necesidades de la víctima, no contribuye a que la persona imputada tenga acceso a la justicia, pues la manera en que se administra dicha institución obstaculiza de forma importante el ejercicio de los derechos reconocidos de esta persona. Tal es el caso del derecho a una defensa adecuada y el derecho de participar en la solución arbitrada.

Estimo que el mayor beneficio de este tipo de instituciones consiste en la posibilidad de permitir a las autoridades cumplir con indicadores de desempeño cuantitativo y administrar su tiempo de acuerdo con el flujo incesante de asuntos que deben resolver. Sin embargo, para tener un mejor diagnóstico de las áreas de oportunidad de la ScP, es necesario emprender una evaluación integral que considere todos los elementos que intervienen en la administración de esta figura. Junto con los balances de eficiencia y eficacia de la SCP, se considera necesario valorar el grado de satisfacción que produce este tipo de solución entre las víctimas y las personas imputadas. Este último punto se torna relevante, pues una percepción de ilegitimidad o injusticia por parte de víctimas o personas imputadas puede comprometer en un futuro su cooperación con el sistema penal. ${ }^{55}$

\section{Bibliografía}

Bergman, M., Azaola, E., Magaloni, A. L., y Negrete, L., Delincuencia, marginalidad y desempeño institucional: resultados de la encuesta a población en reclusión en el Distrito Federal y el Estado de México, Ciudad de México, CIDE, 2003.

Bovino, A., La suspensión del procedimiento penal a prueba en el Código Penal argentino, Argentina, Editores del Puerto, 2001.

Bratthwatte, J., "Diversion, reintegrative shaming and republican criminology", en G. Albrecht (ed.), Diversion and Informal Social Control, Berlin, Walter de Gruyter, 1995.

Chaple, M., Pretrial Diversion \& Record Sealing: A Promising Approach to Reduce Recidivism among Substance Abusing Offenders, Estados Unidos, University of New Jersey, 2011. Disponible en: https://search.proquest.com/openview/ 660407f91200b7ebe70f217bf623f7e3/1?pq-origsite=gscholarEtcbl=18750\&diss $=\mathrm{y}$

\footnotetext{
${ }_{55}$ Tyler, T. R., "Justice and Effective Cooperation", Social Justice Research, vol. 25, núm. 4. Disponible en: http://doi. org/10.1007/s11211-012-0168-5
} 
Daly, K., “The Punishment Debate in Restorative Justice”, en J. Simon \& R. Sparks (eds.), The sage Handbook of Punishment and Society Handbook of Punishment and Society, London, sage Publications, 2013.

DAMASKA, M., "Negotiated Justice in International Criminal Courts", Journal of International Criminal Justice, núm. 2.

FEeLEY, M. M., The process is the punishment: handling cases in a lower criminal court, Nueva York, Russell Sage Foundations, 1992.

FIX-Fierro, H., "Tribunales, justicia y eficiencia”, Estudio sociojurídico sobre la racionalidad económica en la función judicial México, núm. 76.

FlÁvio Gomes, LuIz, "El nuevo paradigma de la justicia criminal consensuada: planteamientos sobre la Ley Brasileña 9.099/95”, Boletín de la Facultad de Derecho, núm. 12.

Fondevila, G., Langer, M., Bergman, M., Vilalta, C. y Mejia, A., “¿Cómo se juzga en el Estado de México?”, México Evalúa. Disponible en: mexicoevalua.org/wpcontent/uploads/2016/10/Como_Juzga_Edomex.pdf

Galain Palermo, P., "La reparación del daño en un sistema penal funcional a las necesidades de la política criminal”, en M. De Hoyos Sancho (ed.), Garantías y derechos de las víctimas especialmente vulnerables en el marco jurídico de la Unión Europea, España, Tirant lo Blanch, 2013.

García Aguilar, R., La suspensión del proceso a prueba en materia penal, San José, Investigaciones Jurídicas, 1998.

Horvitz Lennon, M. I., \& López Masle, J., Derecho procesal penal chileno. Jurídica, Santiago, Editorial Jurídica de Chile, 2002.

Houed Vega, M. A., De la suspensión del proceso a prueba o de la suspensión condicional de la persecución penal, Nicaragua, Instituto de Estudio e Investigación Jurídica, 2007.

Macdonald, S., "Constructing a Framework for Criminal Justice Research: Learning from Packer’s Mistakes”, New Criminal Law Review, vol. 11, núm. 2. Disponible en: http://doi.org/10.1525/nclr.2008.11.2.257

Martínez Monroy, R., Reforma constitucional en materia de justicia penal y seguridad pública. Proceso Legislativo, México, Cámara de Diputados, 2008.

Ortiz de Urbina, I., "Análisis Económico del Derecho y Política Criminal”, Revista de Derecho penal y Criminología, núm. 2.

Riego, C. y Duce, M., Introducción al Nuevo Proceso Penal, Santiago, Universidad Diego Portales, 2002.

RoldÁn, N., “¿Por qué los delitos quedan impunes en la cDMx? Policías narran qué pasa en los MP”. Animal Político, 26 de diciembre. Disponible en: http://www.animalpolitico.com/2016/12/investigacion-policia-impunidad-cdmx/

Siterendurg, Pieter, The spectacle of suffering: Executions and the evolution of repression: From a preindustrial metropolis to the European experience, Cambridge, Cambridge University Press, 1984. 
TAK, Peter, "The Dutch Prosecutor. A Prosecuting and Sentencing Officer", En Erik Luna \&t Marianne Wade (eds.), The Prosecutor in Transnational Perspective, Oxford, Oxford University Press. Disponible en: http://doi.org/10.1093/ acprof:osobl/9780199844807.003.0011

Tulkens, F., “Negotiated Justice”, en M. Delmas-Marty \& J. R. Spencer (eds.), European criminal procedures, Cambridge, Cambridge University Press, 2005.

Tyler, T. R., "Justice and Effective Cooperation”, Social Justice Research, vol. 25, núm. 4. Disponible en: http://doi.org/10.1007/s11211-012-0168-5

unodc, "The Status and Role of Prosecutors. A United Nations Office on Drug and Crime and International Association of Prosecutors Guide", United Nations Office on Drug and Crime. Diponible en: https://www.unodc.org/documents/justice.../14-07304_ebook.pdf

Valverde, M., Ct O’Malley, P., "Criminology”, en M. Valverde (ed.), The Oxford Handbook of Criminal Law, Oxford, Pat O'Malley, 2014.

VAsconcelos Méndez, R., "La suspensión del proceso penal a prueba”, Revista del Instituto de la Judicatura, núm. 123.

Vitale, G. L., Suspensión del proceso penal a prueba, Buenos Aires, Editores del Puerto, 1996. 